\title{
Energy and exergy analysis and optimization of a double flash power plant for Meshkin Shahr region
}

\author{
Mohammad Ameri ${ }^{1, *}$, Saman Amanpour ${ }^{2}$, Saeid Amanpour ${ }^{3}$ \\ ${ }^{1}$ Energy Eng. Department, Power \& Water University of Technology, Tehran, Iran \\ ${ }^{2}$ Department of Aerospace and Mechanical Engineering, Shiraz University, Shiraz, Iran \\ ${ }^{3}$ Department of Electrical Engineering, University Teknologi Malaysia, Johor Darul Takzim, Malaysia \\ * Corresponding author.+9821-73932653, Fax:+9821-77311446,_E-mail: ameri_m@yahoo.com
}

\begin{abstract}
One of the most influential improvements in geothermal industries has been the application of double flash power plants which can produce more power in comparison with single flash one. Although it is more expensive, however it is a reasonable option as the additional output power can justify the prices. The aim of this study is to represent a methodology in which a double flash power plant is thermodynamically designed and optimized in order to maximize the output power, and make a comparison with other possible type of geothermal power plant (single flash) for Meshkin Shahr region. Besides it represents the study of exergy and energy analysis for plant components through the optimization process, which can guide one to assess the operating status of plant components. It has been shown that flash vessels are the greatest exergy dissipaters and double flash power plant can be more efficient than single flash for this region.
\end{abstract}

Keywords: Double Flash Power Plant, Geothermal Power Plant, Energy Analysis, Exergy Analysis, Optimization.

\section{Nomenclature}

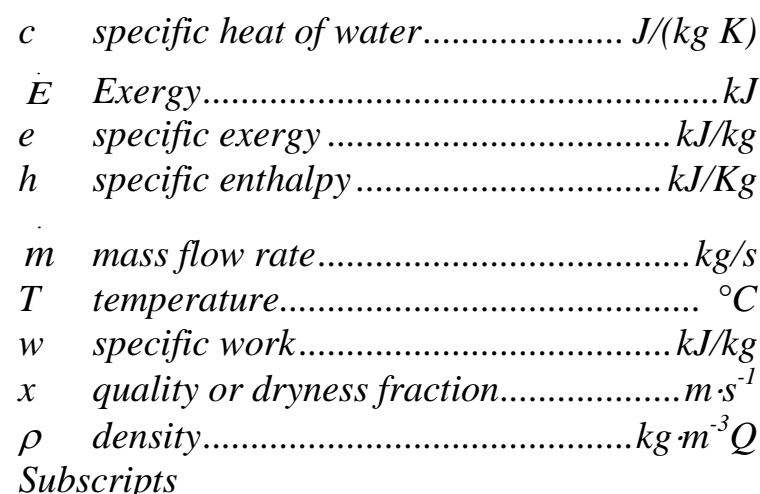

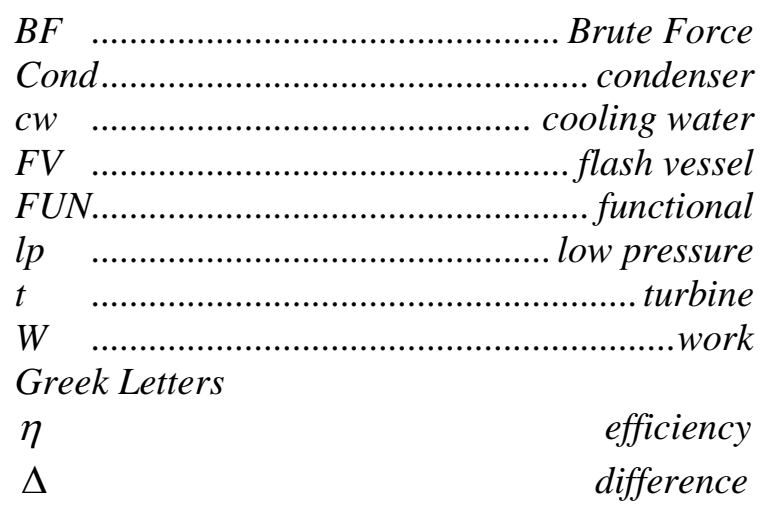

\section{Introduction}

Increasing oil price and environmental concerns about pollution and global warming in recent years has doubled geothermal energy use as a clean source of energy [1]. Today three major types of geothermal power plants are being utilized: dry steam plants, flash steam plants and binary cycle plants [2]. DiPippo has presented some information about new geothermal power plant designs [3]. Flash power plants are likely in liquid-dominated fields with temperature greater than $182^{\circ} \mathrm{C}$ [4]. An important concern in engineering field of geothermal energy is thermodynamic design and optimization of an energy system, especially a power plant, which can reduce the expenses significantly. The application of double flash power plant is not rational for all projects, since the conversion system is more complex and of course more expensive. Stefansson depicted a strategy for the investment costs of geothermal power plants and estimated investment cost level in unknown fields [5]. Therefore, it is important to assess the performance of geothermal plants based on an optimized thermodynamic scheme with respect to the surrounding conditions and thermodynamic state of geothermal reservoir, before putting the plan into action [6]. This can help the designer in better understanding of 
the occasion so that a precise decision can be made to select either a single flash or a double flash plant with respect to costs. Ozcan and Gokcen managed a thermodynamic assessment of single flash power plant and studied the effect of non-condensable gases on plant performance [7]. Dagdas et al. carried out a thermodynamic optimization for a geothermal power plant based on real data and results revealed that $93.2 \%$ more power can be obtained [8]. Franco and Villani found that optimization of binary cycle power plants can yield to reduction of brine specific consumption in a significant way up to $30-40 \%$ [9].

The study of energy and exergy analysis, based on Second Law of Thermodynamics, helps to evaluate the performance of a geothermal power plant in order to eliminate excess energy loss and improve the overall efficiency of the plant [6]. Kanoglu performed an exergy analysis of a binary geothermal power plant using actual plant data and studied the causes of exergy destruction [10]. DiPippo also made comparisons between different cycles of binary plants for low-temperature geothermal fields based on Second Law of Thermodynamics [11].

Bodvardson and Eggers made a comparison between single flash and double flash power plants taking advantage of their exergy tables, as denoted by Yari [1]. Kanoglu and Bolatturk performed an exergy analysis of a binary geothermal power plant, applying actual plant data [2]. Cerci evaluated the performance of a single flash power plant in Turkey by using exergy analysis based on actual plant operation data [12]. He had a debate in the form of response to Serpen who made some comments on performance evaluation of the same project in Turkey concluding that the performance of a geothermal power plant is affected by the chemistry of reservoir $[13,14,15]$. Serpen believed that the design and evaluation of geothermal power plants are subjected to profound study of the geothermal reservoir [13]. Madhawa et al. presented a criterion for cost effective optimum design of organic Rankine cycles based on low temperature geothermal heat sources [16]. Kanoglu et al. did a comprehensive survey on different power cycles including geothermal power plants and presented energy as well as exergy based efficiencies with some illustrative examples [17]. DiPippo also investigated different types of geothermal power generating systems and he applied the exergy analysis to geothermal power systems [3]. Yari did a comparative study of different geothermal power plants based on exergy analysis [1].

This paper represents a two dimensional optimization of a double flash power plant for Meshkin-Shahr region in which the pressure of the first and the second flashing process are optimized by help of a FORTRAN code in order to reach the maximum output power; and the results are sketched in form of 3D surfaces. Moreover, the isentropic efficiency of turbine, brute force and functional efficiency, and exergy dissipation of each plant components are calculated simultaneously in each step of optimization process.

Meshkin-Shahr, a region in the Moil valley which is located on the western slopes of Sabalan Mountain, is a potential geothermal field for power generation. It is the place where the first Iranian geothermal power plant is going to be installed [4]. According to the reservoir type of this region, flash power plants are valid cases for utilization of geothermal energy.

\section{Methodology}

\subsection{Energy and exergy analysis}

Exergy analysis is a thermodynamic analysis technique which is based on second law of thermodynamics. It presents a bright way for evaluation and comparison of processes and systems [18]. This method can be used to estimate the performance of any energy system and 
the combination of this method with energy analysis can assist in elimination of excess energy loss in order to improve the overall efficiency [6]. All the processes in double flash power plant are assumed to be steady state processes. Therefore, the balance equations can be employed to calculate output power, exergy of flow streams and energy and exergy efficiencies. Neglecting the change in kinetic and potential energies, the First Law of Thermodynamics and mass balance equations can be written as:

$$
\begin{aligned}
\dot{Q}-\dot{W} & =\sum\left(\dot{m}_{e} h_{e}-\dot{m}_{i} h_{i}\right) \\
\sum \dot{m}_{i} & =\sum \dot{m}_{e}
\end{aligned}
$$

The second law of thermodynamics for a perfect reversible process and the specific exergy of a fluid stream associated to dead state condition can be stated by Eq. (3) and Eq. (4) respectively. The subscribe " $0 "$ represents dead state condition at $20^{\circ} \mathrm{C}$ and $1 \mathrm{~atm}$.

$$
\begin{aligned}
& \sum\left(\dot{m}_{e} s_{e}-\dot{m}_{i} s_{i}\right)-\frac{\dot{Q}_{0}}{T_{0}}=0 \\
& e=h-h_{0}-T_{0}\left(s-s_{0}\right)
\end{aligned}
$$

\subsection{Thermodynamic nature of processes in double flash power plants}

Double flash power plant as a choice of energy conversion system for liquid-dominated fields, constitute about $14 \%$ of all geothermal plants with the power capacity ranges from $4.7 \mathrm{MW}$ to $110 \mathrm{MW}$ [3]. A T-S schematic diagram of a double flash power plant is shown in Fig. 1.

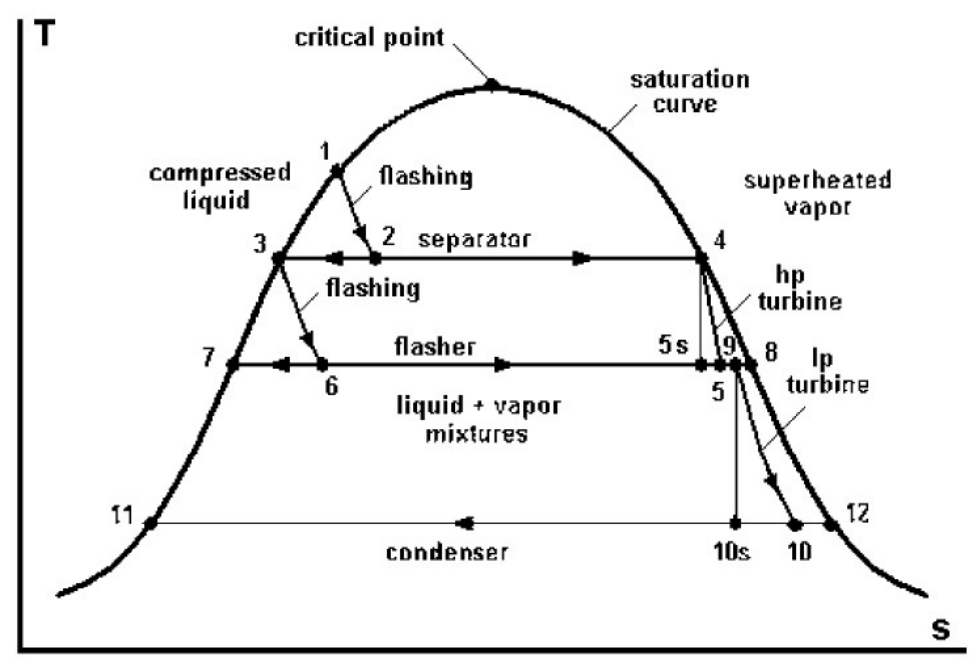

Fig. 1. Temperature-Entropy diagram of a double flash power plant.

Two phase fluid from geothermal wells is pumped to power plant on the ground surface at condition near saturation and it can be assumed as pressurized liquid (point 1 in Fig. 1). The pressurized liquid undergoes the first flashing process by passing through a throttle valve so its pressure falls in an isenthalpic process, where a two phase fluid is produced (point 2 in Fig. 1). These two phases are separated in a high pressure separator where the steam is guided to 
drive the high pressure turbine (point 4 in Fig. 1) and the liquid phase undergone the second flashing process (point $3 \mathrm{in}$ Fig. 1) and the two phases are separated efficiently. The low pressure steam of this process is guided toward a dual-admission turbine or it is guided toward a separate low pressure turbine (point 9 in Fig. 1) and the liquid phase is disposed to the injection wells (point 7 in Fig. 1). The two phased mixture of turbine exhaust will be then condensed in a condenser and disposed into injection wells (point 11 in Fig. 1). The enthalpy of actual turbines' processes can be easily calculated by incorporating fluid properties at state $5 \mathrm{~s}$ and $10 \mathrm{~s}$ and the efficiency of turbines as well as the Baumann rule. This rule states that since the turbine processes take place in wet region, there would be a $1 \%$ drop in efficiency of turbines per every percent of average moisture. Thus for low pressure turbine one may write:

$$
h_{10}=\frac{h_{9}-0.425\left(h_{9}-h_{10 s}\right)\left(x_{9}-\frac{h_{11}}{h_{12}-h_{11}}\right)}{1+\frac{0.425\left(h_{9}-h_{10 s}\right)}{h_{12}-h_{11}}}
$$

Properties at state 9 can be easily gained by combination of First Law of Thermodynamics and mass conservation and the condensation process is assumed to take place in a constant pressure process, and effects of non-condensable gases are neglected.

\subsection{Exergy efficiencies and exergy dissipations of double flash power plant}

There are two different approaches for the definition of exergy efficiencies. Brute force efficiency, defined as the sum of all output exergy terms divided by the sum of all input exergy terms, and functional efficiency, defined as the exergy of desired energy output divided by the exergy spent to achieve the desired output [3]. According to Fig.1, exergy dissipations and exergy efficiencies of a double flash power plant's components can be expressed as follows, for brevity we just point out some of the relations and others can be written in a similar way [3].

$\Delta \dot{E}_{F V 2}=m_{3} e_{3}-m_{7} e_{7}-m_{9} e_{9}$

$\eta_{F V 2, B F}=\frac{\dot{m}_{7} e_{7}+\dot{m}_{9} e_{9}}{\dot{m}_{3} e_{3}}$

$$
\eta_{F V 2, F U C}=\frac{m_{9} e_{9}}{\dot{m}_{3} e_{3}}
$$

$\eta_{t l p, B F}=\frac{w_{l p}+e_{5}}{e_{4}}$

$$
\eta_{t l p, F U N}=\frac{w_{h p}}{e_{4}-e_{5}}
$$


The functional efficiency for condenser can be estimated by two different approaches based on the nature of unit [3].

\section{Results}

The methodology which is used in this paper is based on assumptions pointed out in table 1 and piping losses are assumed to be negligible. "Equal-temperature-split" rule [3] is a usual method for the selection of temperature (or pressure) of separation process in order to approach the optimum state which leads to maximum output power. This rule cannot define the exact pressure since processes take place in two phase region. However, it can lead one to the verge of best option. The precise pressures require a two-dimensional optimization on vicinity of pressures estimated by "equal-temperature-split" rule. Fig. 2 illustrates a twodimensional optimization in form of a saddle shaped surface where the maximum vertical point illustrates the maximum output power which is equal to $67793.04 \mathrm{KJ}$. This power is the total power produced by high pressure and low pressure turbines and it seems that double flash power plant can produce about $13-14 \%$ more power than single flash one [6]. The related pressures to this point are $0.67 \mathrm{MPa}$ and $0.1 \mathrm{MPa}$ for the first and second separation processes respectively. It is worth to mention that P2 and P6 in the following figures are adopted from Fig. 1.

Table 1. Fixed and variable parameters.

\begin{tabular}{lllll}
\hline Parameter & Status & Possible range & \\
\hline Inlet temperature & $225^{\circ} \mathrm{C}$ (based on reservoir & Temperatures greater & than \\
& condition) & $180^{\circ} \mathrm{C}[4]$ & & \\
Inlet mass flow rate & $700 \mathrm{~kg} / \mathrm{s}$ & - & & \\
Separators' pressure & Variable (optimized) & $100-1000 \mathrm{KPa}[19]$ & \\
Condensation pressure & Fixed at $10 \mathrm{KPa}$ & Recommended $8-10$ & $\mathrm{KPa}$ \\
& & {$[19]$} & & \\
\hline
\end{tabular}

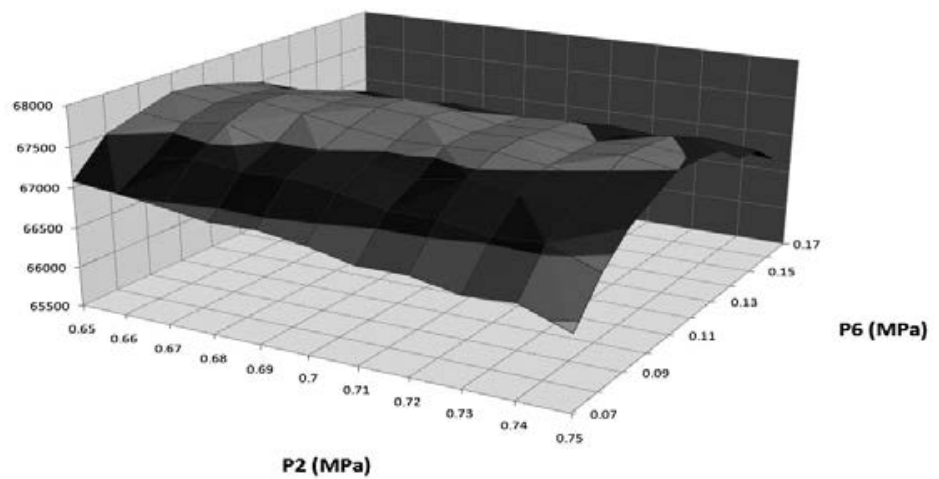

Fig. 2. Two dimensional optimization for output power (KJ).

Fig. 3 shows the effect of pressure change on the isentropic efficiencies of high pressure and low pressure turbines. It is obvious that the effect of separation pressures on isentropic efficiency of high pressure and low pressure turbines is somehow in opposite directions. Total exergy dissipations of turbines, flash vessels and condenser are illustrated in Fig. 4 and Fig. 5. It seems flash vessels are the greatest exergy dissipators in power plant and small changes in pressures can lead to a dramatic change in exergy dissipation of flash vessels. 


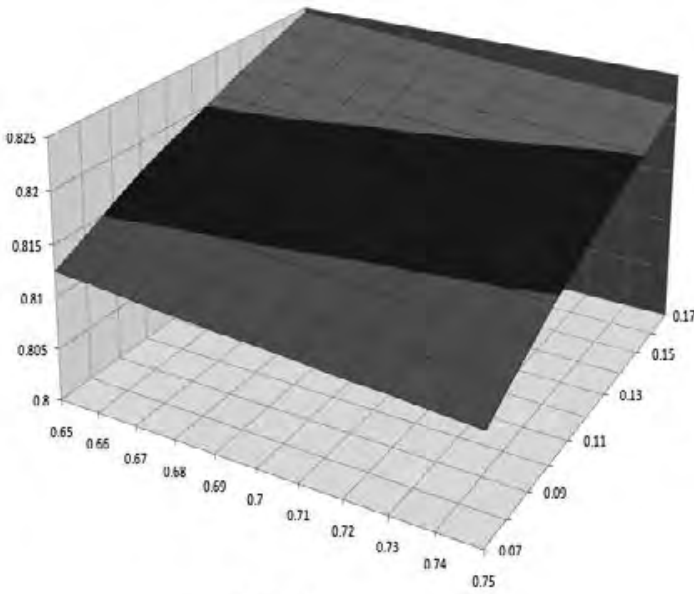

$\mathrm{P2}$ (MPa)

(a)

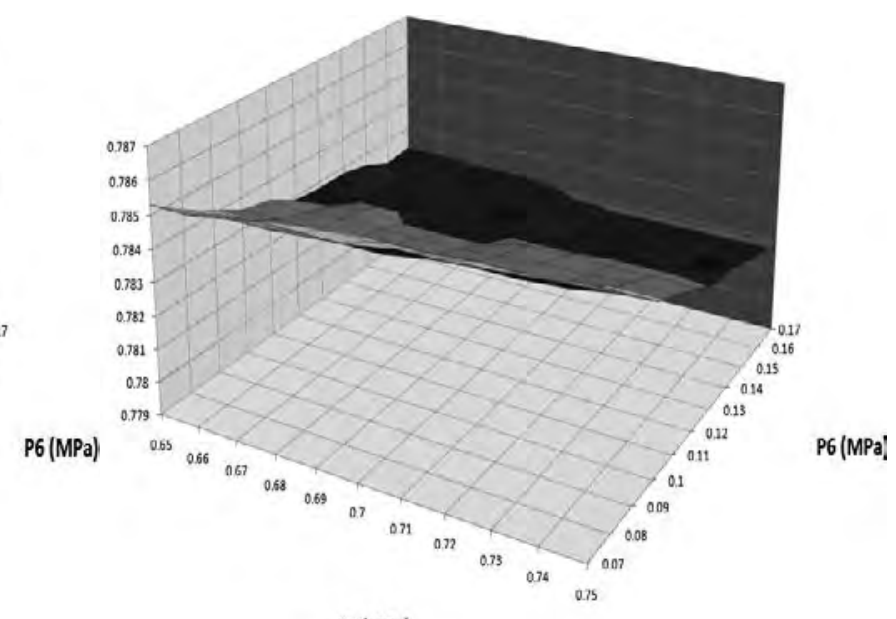

$\mathrm{P2}$ (MPa)

(b)

Fig. 3. Isentropic efficiency for (a) High pressure turbine (b) Low pressure turbine.

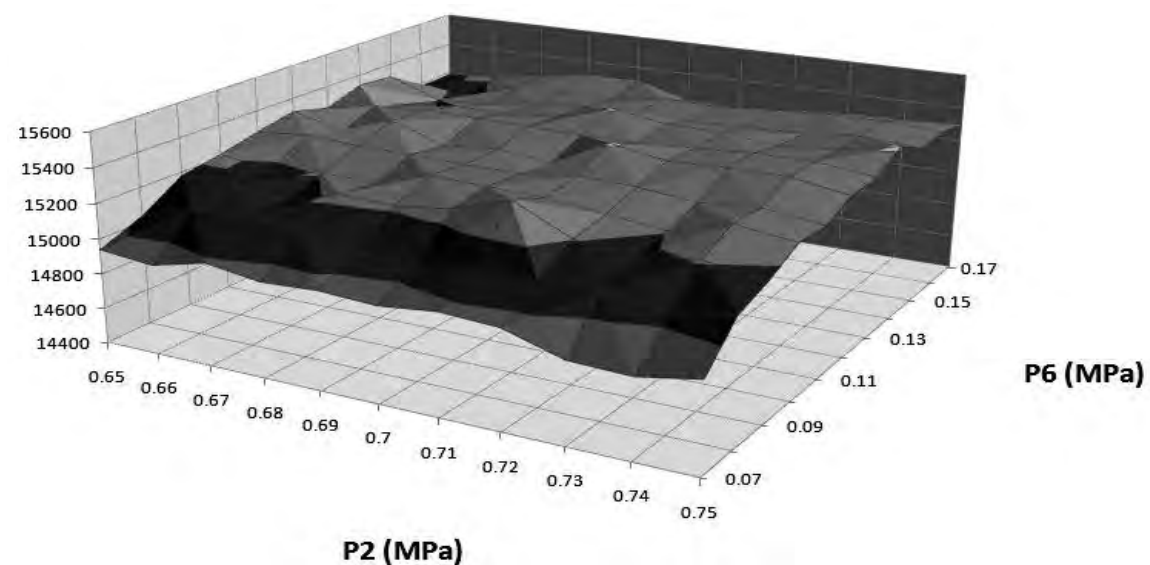

Fig.4. Total exergy dissipation of turbines $(\mathrm{KJ})$.

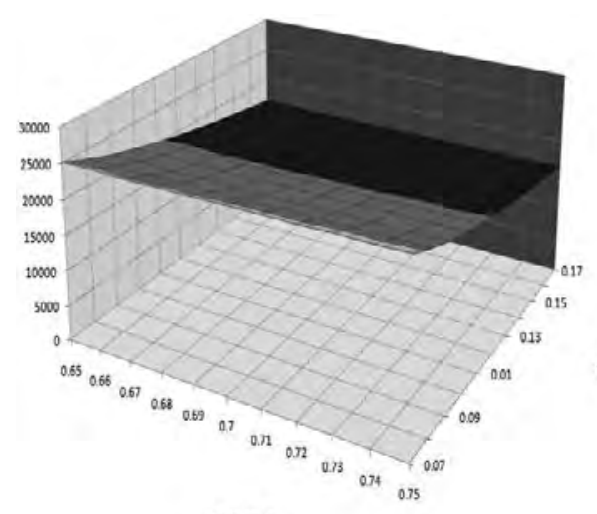

$\mathrm{P2}$ (MPa)

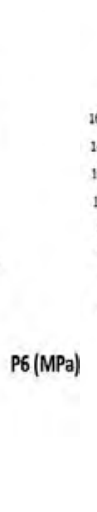

(a)

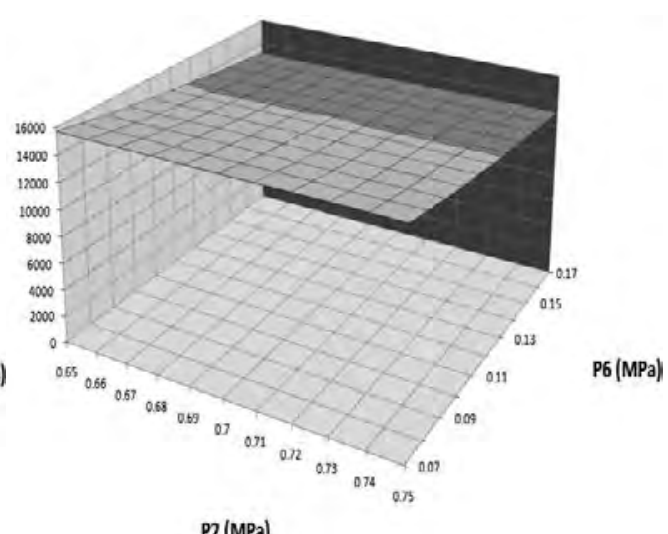

(b)

Fig. 5. Total exergy dissipation (KJ) (a) Flash vessels (b) Condenser.

\section{Discussion and Conclusions}

As there is no data available for Meshkin-Shahr power plant, the validation of this study is done for a geothermal power plant in Turkey [19]. It shows good agreement. However, the validation is limited to annual net output power. The results of our study demonstrate that the exergy efficiencies of high pressure and low pressure turbines change in opposite directions. Brute force efficiency can reveal how much exergy of incoming flow is utilized and how 
much is lost. On the other hand functional efficiency can disclose how much of incoming exergy is conserved in flow stream and how much leaves the component.

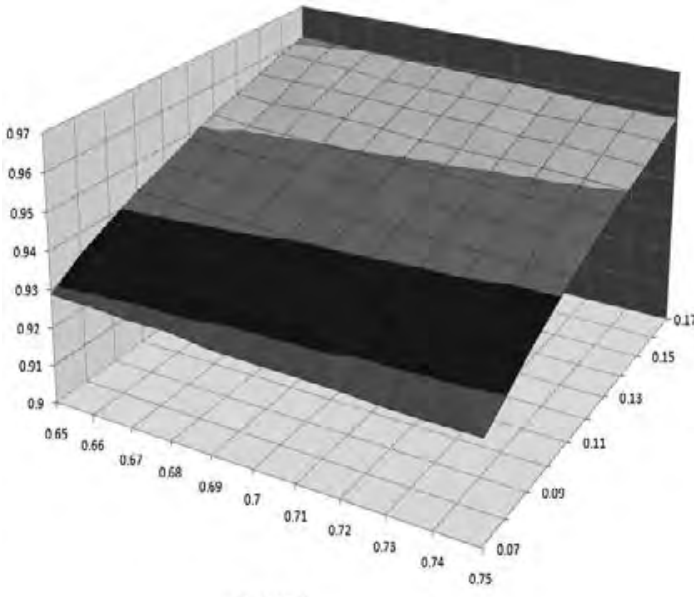

P2 (MPa)

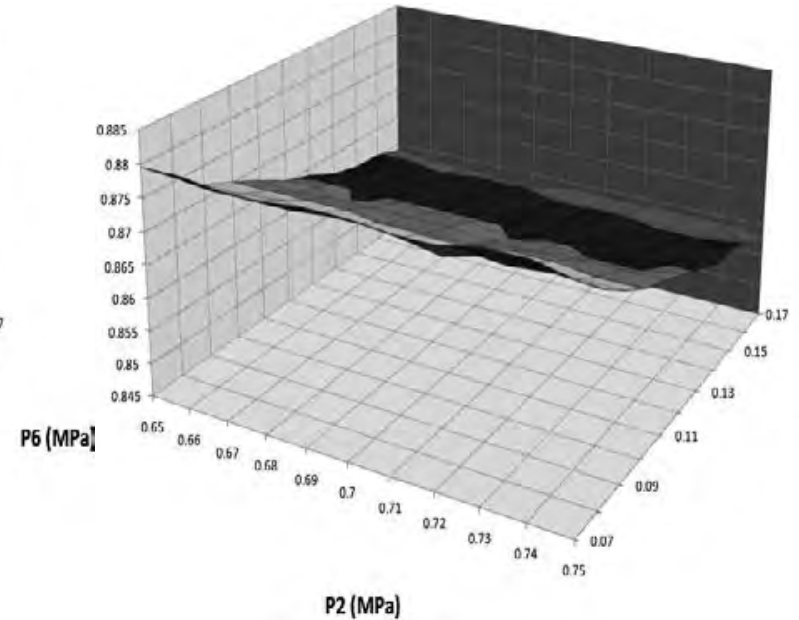

(b)

Fig. 6. Brute force efficiency (a) High pressure turbine (b) Low Pressure turbine.

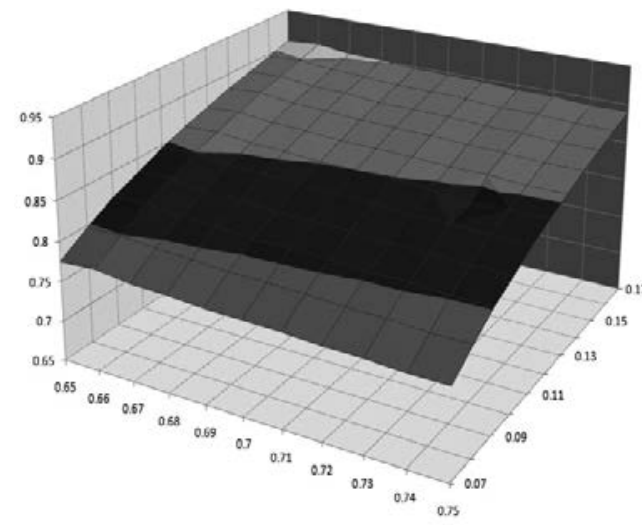

P2 (MPa)

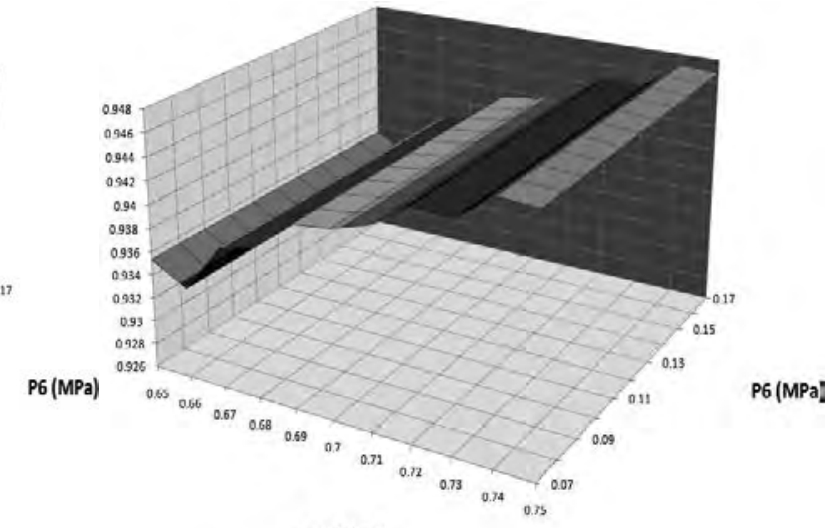

P2 (MPa)

(b)

Fig. 7. Brute force efficiency (a) Low pressure flash vessel (b) High pressure flash vessel.

The suffered brute force and isentropic efficiencies of low pressure turbine in comparison with high pressure turbine is due to the fact that more amount of incoming exergy has left the turbine. A more profound study of Fig. 6 and having in mind that in double flash power plants low pressure turbines have greater portion in output power production, one can easily find why the optimum point for pressures is situated in the intersection of $0.67 \mathrm{MPa}$ and $0.1 \mathrm{MPa}$. Since the pressure of incoming flow to high pressure flash vessel is constant, one can easily understand why the brute force efficiency surface is like sets of stairs.

\section{References}

[1] M. Yari, Exergetic analysis of various types of geothermal power plants, Renewable Energy 35, 2010, pp. 112-121.

[2] M. Kanoglu, A. Bolatturk, Performance and parametric investigation of a b inary geothermal power plant by exergy, Renewable Energy 33, 2008, pp. 2366-2374.

[3] R. DiPippo, Geothermal power plants, Elsevier Ltd, 2nd Edition, 2007, pp. 191 -251 \& 102-104 \& 241-247. 
[4] M. Ameri, S.R. Shamshirgaran, M. Pour Yousefi, The Study of Key Thermodynamic Parameters Effect on the Performance of a Flash Steam Geothermal Power Plant, Proceeding of 2nd Joint Int. Conference SEE 2006, Bangkok, 2006, B-004 (O).

[5] V. Stefansson, Investment cost for geothermal power plants, Geothermics 31, 2002, pp. 263-272.

[6] M. Ameri, S. Amanpour, S. Amanpour, Energy and exergy analysis of Mehkin-Shahr single flash geothermal power plant, Proceeding of 10th International Conference on Clean Energy (ICCE-2010), 2010, No. 12-08.

[7] N. Y. Ozcan, G. Gokcen, Thermodynamic assessment of gas removal systems for singleflash geothermal power plants, Applied Thermal Engineering 29, 2009, pp. 3246-3253.

[8] A. Dagdas, R. Ozturk, S. Bekdemir, Thermodynamic evaluation of Denizli Kizildere geothermal power plant and its performance improvement, Energy Conversion and Management 46, 2005, pp. 245-256.

[9] A. Franco, M. Villani, Optimal design of binary cycle power plants for water-dominated, medium-temperature geothermal fields, Geothermics 38, 2009, pp. 379-391.

[10]M. Kanoglu, Exergy analysis of a dual-level binary geothermal power plant, Geothermics 31, 2002, pp. 709-724.

[11]R. DiPippo, Second Law assessment of binary plants generating power from lowtemperature geothermal fluids, Geothermics 33, 2004, pp. 565-586.

[12] Y. Cerci, Performance evaluation of a single-flash geothermal power plant in Denizli, Turkey, Energy 28, 2003, pp. 27-35.

[13]U. Serpen, Comments on Performance evaluation of single-flash geothermal power plant in Denizli, Turkey, Energy 29, 2004, pp. 1219-1223.

[14]Y. Cerci, Response to comments on "Performance evaluation of single-flash geothermal power plant in Denizli, Turkey", Energy 29, 2004, pp. 1225-1226.

[15]U. Serpen, Reply to the author's response to comments on "Performance evaluation of single-flash geothermal power plant in Denizli, Turkey", Energy 29, 2004, pp.1227-1229.

[16]H.D. Madhawa Hettiarachchi, M. Golubovic, M. Worek William, Y. Ikegami, Optimum design criteria for an Organic Rankine cycle using low-temperature geothermal heat sources, Energy 32, 2007, pp. 1698-1706.

[17]M. Kanoglu, I. Dincer, A. Rosen Mark, Understanding energy and exergy efficiencies for improved energy management in power plants, Energy Policy 35, 2007, pp. 3967-3978.

[18]I. Dincer, M. Rosen, Exergy, Elsevier Ltd, 2007, pp. 23-24.

[19]N. YILDIRIM OZCAN, modeling, simulation and optimization of flashed-steam geothermal power plants from the point of view of non-condensable gas removal systems, $\mathrm{PhD}$ thesis, Graduate School of Engineering and Science of Izmir Institute of Technology, 2010, pp. 82-83 \& 149-150. 